\title{
A national estimate of the birth prevalence of congenital anomalies in India: systematic review and meta-analysis
}

Prajkta Bhide and Anita Kar ${ }^{*}$ (i)

\begin{abstract}
Background: A quarter of all global neonatal deaths occur in India. Congenital anomalies constitute the fifth largest cause of neonatal mortality in the country, but national estimates of the prevalence of these conditions are lacking. The objective of the study was to derive an estimate of the birth prevalence of congenital anomalies in India.

Methods: The search was carried out in PubMed and pooled prevalence was estimated using the inverse variance method. A random effects model was used due to high heterogeneity between the studies. Forest plots were generated using the Review Manager software.

Results: The PubMed search identified 878 articles from which 52 hospital based and three community based studies were included in the meta-analysis. The pooled prevalence of congenital anomaly affected births was 184 . 48 per 10,000 births (95\% Cl 164.74-204.21) among 802,658 births. Anomalies of the musculoskeletal system were highest among live births while the prevalence of central nervous system defects was highest when stillbirths were included in the analysis. Anencephaly and talipes were the most commonly reported anomalies.

Conclusions: Data from this meta-analysis suggests that there may be as many as $472,177(421,652$ to 522,676$)$ congenital anomaly affected births in India each year. Population based studies using standard definitions are needed to validate these estimates. The two most frequently reported anomalies were anencephaly that is potentially preventable through preconception folate supplementation, and talipes which can be corrected using relatively low cost interventions. Studies are needed to determine the impact of congenital anomalies on neonatal mortality in India.
\end{abstract}

Keywords: Birth defects, Congenital anomalies, Congenital malformations, Birth prevalence, India, Meta-analysis

\section{Background}

A quarter of global neonatal deaths occur in India. In 2013 , the country reported a neonatal mortality rate of 29 per 1000 live births, responsible for 753,000 neonatal deaths [1]. While the highest contributors to neonatal deaths were preterm births (34.7\%), intrapartum complications (19.6\%), pneumonia (16.3\%) and neonatal sepsis (15\%), congenital anomalies constituted the fifth largest cause, being responsible for an estimated $9 \%$ of neonatal deaths in the year 2010 [2]. There is evidence of transition in causes of infant and child mortality in low and

\footnotetext{
* Correspondence: akar@unipune.ac.in

Interdisciplinary School of Health Sciences, Savitribai Phule Pune University, Pune 411007, India
}

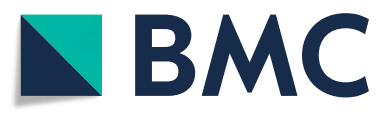

(c) The Author(s). 2018 Open Access This article is distributed under the terms of the Creative Commons Attribution 4.0 International License (http://creativecommons.org/licenses/by/4.0/), which permits unrestricted use, distribution, and reproduction in any medium, provided you give appropriate credit to the original author(s) and the source, provide a link to the Creative Commons license, and indicate if changes were made. The Creative Commons Public Domain Dedication waiver (http://creativecommons.org/publicdomain/zero/1.0/) applies to the data made available in this article, unless otherwise stated. middle-income countries, including India [3]. With a decrease in infectious causes of infant deaths, especially in urban areas in India, the proportion of mortality due to congenital anomalies is likely to increase [4]. Global estimates suggest that congenital anomalies affect 2-3\% of births [5]. Assuming a $2 \%$ birth prevalence, and 25,595,000 births in 2013 [6], an estimated 511,900 births may have been affected with a congenital anomaly in India. These estimates exceed the combined totals of anomaly affected births occurring in several high-income countries [7]. The true magnitude of the number of births affected by congenital anomalies in India is unknown due to lack of a national birth defects surveillance. The need for data arises as currently there 
is no data on the impact of congenital anomaly affected pregnancies or births on health service utilization, for either termination of pregnancy due to detection of a fetal anomaly or for neonatal intensive care services. Another requirement for data is to derive estimates of the number of children born with disabling conditions. Medical and rehabilitative services for affected children through government health services are currently limited in India, resulting in significant out of pocket expenditure for families $[8,9]$. Data on the magnitude of congenital anomalies are also needed as some of these conditions can be prevented through primary care interventions targeted towards women in the preconception, intra-conception and antenatal periods [10]. Strategies targeting the prevention of births affected by congenital anomalies also target the shared risk factors for other adverse pregnancy outcomes, effectively aiming at reduction of reproductive wastage, and improving pregnancy outcome [11]. In this study, we systematically reviewed available Indian studies, in order to derive a national estimate of births affected by congenital anomalies in India. We also discuss the implications of this quantitative analysis in terms of prevention and care, further research needs, and the characteristics of a birth defects surveillance system in India.

\section{Methods}

\section{Search strategy}

A literature search was performed in PubMed in April 2015 using the keywords: ("congenital abnormalities"[MeSH Terms] OR ("congenital"[All Fields] AND "abnormalities"[All Fields]) OR "congenital abnormalities"[All Fields] OR ("congenital"[All Fields] AND "anomalie$\mathrm{s}$ "[All Fields]) OR “congenital anomalies"[All Fields]) AND ("epidemiology"[Subheading] OR "epidemiology"[All Fields] OR "prevalence"[All Fields] OR "prevalence"[MeSH Terms]) AND ("india"[MeSH Terms] OR "india"[All Fields]). No restrictions were used for date of publication. Further searches were carried out among the reference lists of eligible articles.

\section{Study selection}

All titles and abstracts identified in the PubMed search were screened for the possibility of extracting birth prevalence data. Studies were eligible to be included in the review if they fulfilled the following inclusion criteria: 1) reported data on the number of anomaly affected babies or anomalies identified at birth among either live born and/or stillborn babies and 2) were conducted in India. Exclusion criteria: 1) Case reports and papers focusing on etiology, diagnosis or clinical management were excluded. 2) Studies that reported prevalence data of only a single anomaly or system were not included in the analysis as these represented non-random, selected cases, and would therefore distort prevalence estimates.

\section{Data quality}

Studies were included if: 1) a clear description of study setting (hospital or community-based) was mentioned, 2) study reported total number of births in the given time period, and 3) number and type (live or stillbirth) of anomaly affected births amongst the total births was mentioned.

\section{Data extraction}

A data extraction form was designed in MS Excel for the following study characteristics: study and geographical setting, study duration, sample size, and primary outcomes of interest which included the number of anomaly affected babies or the number of anomalies and the number of births (live and stillbirths) as reported in the study. When a study was eligible for inclusion in the review, the numerator and denominator were verified and the prevalence estimate was recalculated.

\section{Statistical analysis}

Birth prevalence of congenital anomalies was calculated as the total number of babies (both live born and stillborn) with anomalies per 10,000 births [12]. The live birth prevalence was determined from the number of anomaly affected live births per 10,000 live births [12] Pooled prevalence was estimated in Review Manager (version 5.3) software using the inverse variance method. Due to the high heterogeneity between studies $\left(I^{2}>95 \%\right.$, $p<0.05)$ the meta-analysis was conducted using a random-effects model.

\section{Results}

\section{Search results}

The PubMed search identified 878 articles, of which only 50 articles were identified to be of potential interest for inclusion in the review. A search of the reference lists of these 50 articles yielded a further 17 articles of potential interest, published in non-indexed Indian journals. Finally 54 articles fulfilled the inclusion criteria and were included in the review (Fig. 1).

\section{Study characteristics}

There were 52 hospital-based [13-63] and three community-based studies [64-66] (one article [58] reported two separate studies conducted in Mumbai (39,498 births) and Kolkata (19,191 births)). These 55 studies were reported between 1960 and 2015 (Table 1). Clinical examination was the major method of case ascertainment and was backed up only in 14 studies by radiological, ultrasound and other investigations [17, 20, 22, 23, 26-28, 33, 40, 48, 50-52, 60]. Nine studies 


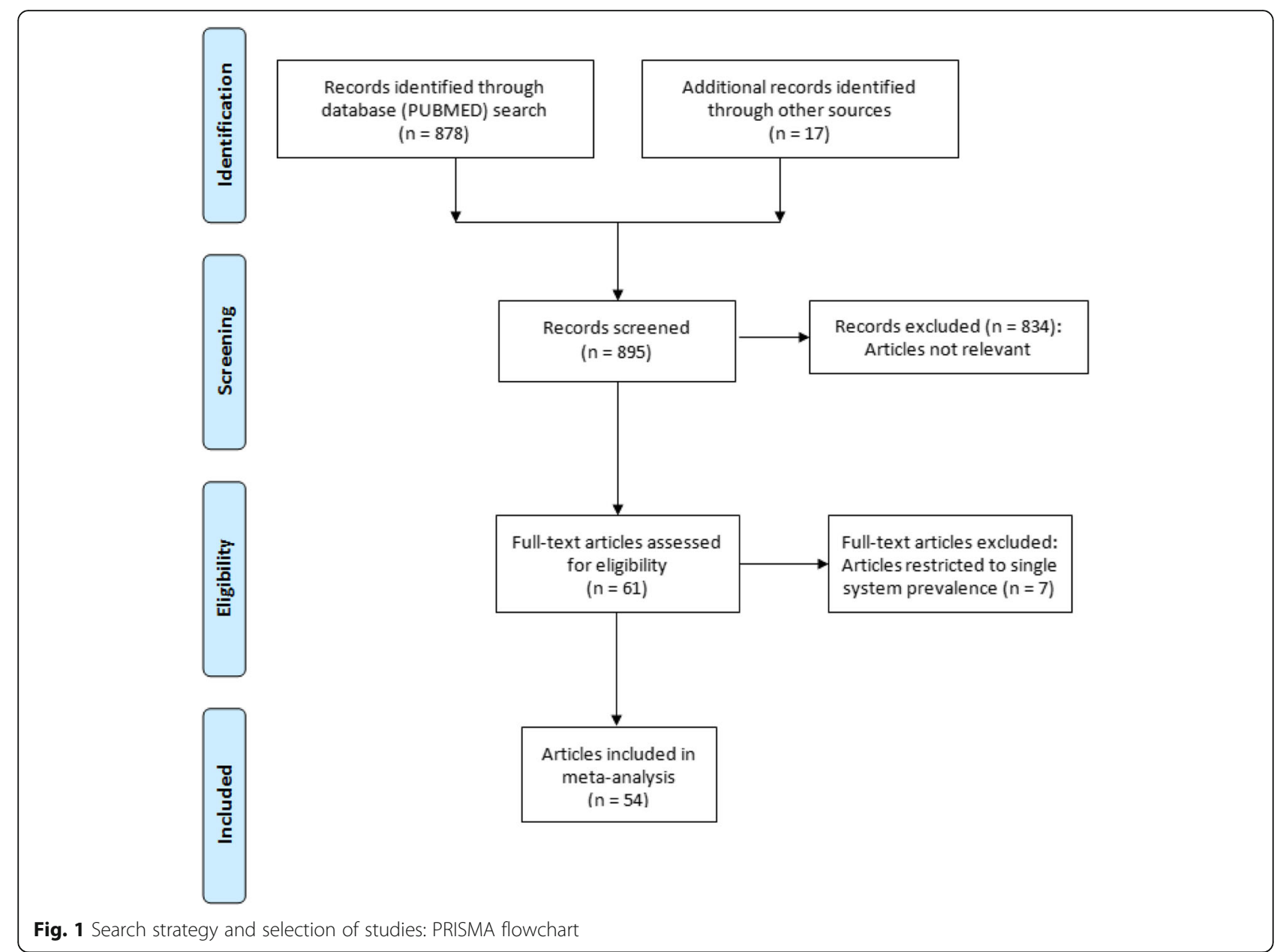

reported the involvement of neonatologists or pediatricians in case ascertainment $[19,26,35,39,45,49,51$, $62,64]$. The autopsy rate varied among the hospital studies ranging from 0 to $25 \%$ for stillbirths and early neonatal deaths. None of the studies reported the number of pregnancies terminated due to detection of fetal anomalies. Community studies were restricted to live births and did not report stillbirths and early neonatal deaths.

\section{Birth prevalence of congenital anomalies}

Data on births affected by congenital anomalies was reported from 52 hospital-based studies of which 47 studies reported both live and stillbirths while five studies reported only live births. The number of births screened ranged from 1000 to 141,540 for hospital-based studies. The reporting of anomalies was done during the period of hospital stay till discharge. The pooled prevalence of congenital anomaly affected births from 802,658 births using a random-effects model was 184.48 per 10,000 births (95\% CI 164.74-204.21) (Fig. 2a). The five hospital-based studies reported a pooled live birth prevalence of 203.33 per 10,000 live births (95\% CI 171.32-235.34) for 44,392 live births (Fig. 2b).

Community-based studies reported the prevalence of anomaly affected births within the first week post birth. The studies reported screening of live births ranging from 194 to 7590 live births. The pooled prevalence for community studies from 10,193 live births was 261.05 per 10,000 live births (95\% CI 199.13-322.96) (Fig. 2c). Due to paucity of studies, analysis of congenital anomaly prevalence rates over time did not yield meaningful results.

\section{System-wise prevalence of anomalies}

Table 2 presents the system-wise prevalence of anomalies. Among hospital studies, which included data on both live births and stillbirths, anomalies of the central nervous system were most frequently reported, followed by anomalies of the musculoskeletal system (75.85 per 10,000 births (95\% CI 58.80-92.90) and 65.64 per 10,000 births (95\% CI 52.97-78.31), respectively). Cardiovascular system anomalies had the lowest birth prevalence across both hospital and community settings. Among 
Table 1 Characteristics of studies included in the review $(n=55)$

\begin{tabular}{|c|c|c|c|c|c|c|c|}
\hline Study & Study period & Study setting & Duration & Place & $\begin{array}{l}\text { Number } \\
\text { of births }\end{array}$ & $\begin{array}{l}\text { Number of anomaly } \\
\text { affected births }\end{array}$ & $\begin{array}{l}\text { Birth prevalence } \\
\text { per 10,000 births }\end{array}$ \\
\hline Agarwal et al. 1991 [13] & $1981-1984$ & hospital & 31.5 months & Lucknow & 9405 births & 192 & 204.15 \\
\hline Agarwal et al. 2014 [14] & 2010-2011 & hospital & 12 months & Bhubaneswar & 7268 births & 116 & 159.6 \\
\hline Aiyar and Agarwal 1969 [15] & 1966-1967 & hospital & 19 months & Mumbai & $\begin{array}{l}10,000 \text { live } \\
\text { births }\end{array}$ & 172 & $172^{\mathrm{a}}$ \\
\hline Anand et al. 1988 [16] & NM & hospital & NM & Jamnagar & 2000 births & 40 & 200 \\
\hline Bai et al. 1982 [17] & NM & hospital ${ }^{\mathrm{b}}$ & 12 months & Trivandrum & 7167 births & 132 & 184.18 \\
\hline Bai et al. 1990 [18] & NM & hospital & 12 months & Trivandrum & 13,964 births & 50 & 35.81 \\
\hline Baruah et al. 2015 [19] & 2010-2013 & hospital & 34 months & Dibrugarh & 18,192 births & 206 & 113.24 \\
\hline Bharucha 1998 [20] & 1993-1996 & hospital $^{\text {b }}$ & 39 months & Mumbai & 42,304 births & 972 & 229.77 \\
\hline Bhat and Babu 1998 [21] & 1989-1992 & hospital & 40 months & Pondicherry & 12,797 births & 353 & 275.85 \\
\hline $\begin{array}{l}\text { Chaturvedi and Banerjee } \\
1989 \text { [22] }\end{array}$ & 1985-1986 & hospital $^{\text {b }}$ & 12 months & Wardha & 3014 births & 82 & 272.06 \\
\hline Chinara and Singh 1982 [23] & 1978-1979 & hospital $^{b}$ & 12 months & Varanasi & 1774 births & 37 & 208.57 \\
\hline Choudhary et al. 1984 [24] & 1976-1980 & hospital & 60 months & Kolkata & 21,016 births & 63 & 29.98 \\
\hline Choudhary et al. 1989 [25] & 1976-1987 & hospital & 120 months & Kolkata & $\begin{array}{l}\text { 126,266 } \\
\text { births }\end{array}$ & 535 & 42.37 \\
\hline $\begin{array}{l}\text { Christopher and Jadhav } \\
1986 \text { [26] }\end{array}$ & 1979-1983 & hospital $^{\mathrm{b}}$ & 60 months & Vellore & 21,585 births & 131 & 60.69 \\
\hline Desai and Desai 2006 [27] & NM & hospital ${ }^{\mathrm{b}}$ & 12 months & Mumbai & 2188 births & 79 & 361.06 \\
\hline $\begin{array}{l}\text { Dutta and Chaturvedi } 2000 \\
\text { [28] }\end{array}$ & 1998-1999 & hospital $^{b}$ & 13 months & Wardha & 2968 births & 37 & 124.66 \\
\hline $\begin{array}{l}\text { Duttachoudhary and Pal } \\
1997 \text { [29] }\end{array}$ & 1991-1993 & hospital & 36 months & Durgapur & 7242 births & 26 & 35.9 \\
\hline Ghosh et al. 1979 [30] & 1974-1976 & hospital & 29 months & Kolkata & 2019 births & 29 & 143.64 \\
\hline Ghosh et al. 1985 [64] & 1969-1973 & community & 40 months & New Delhi & $\begin{array}{l}7590 \text { live } \\
\text { births }\end{array}$ & 189 & $249.01^{\mathrm{a}}$ \\
\hline $\begin{array}{l}\text { Goravalingappa and Nashi } \\
1979 \text { [31] }\end{array}$ & 1986-1987 & hospital & 15 months & Hubli & 2398 births & 75 & 312.76 \\
\hline Grover 2000 [32] & 1991-1995 & hospital & 60 months & Shimla & 10,100 births & 180 & 178.22 \\
\hline Hemrajani et al. 1971 [33] & $1965-1969$ & hospital $^{\text {b }}$ & 60 months & Jaipur & 28,511 births & 608 & 213.25 \\
\hline Jaikrishan et al. 1999 [34] & 1995-1998 & hospital & 41 months & Kerala & 36,805 births & 538 & 146.18 \\
\hline Jaikrishan et al. 2013 [35] & 1995-2011 & hospital & 191 months & Kerala & $\begin{array}{l}141,540 \\
\text { births }\end{array}$ & 1370 & 96.79 \\
\hline Joseph et al. 2010 [65] & 2004-2005 & community & 6 months & Belgaum & $\begin{array}{l}194 \text { live } \\
\text { births }\end{array}$ & 4 & $206.19^{a}$ \\
\hline Khanna and Prasad 1967 [36] & 1964 & hospital & 9 months & Patna & 5376 births & 74 & 137.65 \\
\hline Kolah et al. 1967 [37] & $1960-1963$ & hospital & 39 months & Mumbai & 23,568 births & 331 & 140.44 \\
\hline Kulkarni et al. 1987 [38] & 1984 & hospital & 6 months & Davangere & 2000 births & 81 & 405 \\
\hline Kulshetra et al. 1983 [66] & 1976-1977 & community & 24 months & Ballabhgarh & $\begin{array}{l}2409 \text { live } \\
\text { births }\end{array}$ & 79 & $327.94^{\mathrm{a}}$ \\
\hline Marwah et al. 2014 [39] & 2010-2011 & hospital & 12 months & Patiala & 1554 births & 69 & 444.02 \\
\hline Mathur et al. 1975 [40] & 1970 & hospital $^{\text {b }}$ & 4 months & Hyderabad & 1060 births & 33 & 311.32 \\
\hline Mishra and Baveja 1989 [41] & 1983-1987 & hospital & 48 months & Allahabad & 4098 births & 60 & 146.41 \\
\hline Mital and Grewal 1969 [42] & $1967-1968$ & hospital & 15 months & Kanpur & 4150 births & 93 & 224.1 \\
\hline Modi et al. 1998 [43] & 1993-1997 & hospital & 40 months & Baroda & 31,775 births & 651 & 204.88 \\
\hline Parmar et al. 2010 [44] & $2006-2007$ & hospital & 18 months & Bhavngar & 4210 births & 37 & 87.89 \\
\hline Patel and Adhia 2005 [45] & NM & hospital & 24 months & Mumbai & 17,653 births & 294 & 166.54 \\
\hline
\end{tabular}


Table 1 Characteristics of studies included in the review $(n=55)$ (Continued)

\begin{tabular}{|c|c|c|c|c|c|c|c|}
\hline Study & Study period & Study setting & Duration & Place & $\begin{array}{l}\text { Number } \\
\text { of births }\end{array}$ & $\begin{array}{l}\text { Number of anomaly } \\
\text { affected births }\end{array}$ & $\begin{array}{l}\text { Birth prevalence } \\
\text { per 10,000 births }\end{array}$ \\
\hline Patel et al. 2014 [46] & $2012-2014$ & hospital & 24 months & Ahmedabad & 16,481 births & 210 & 127.42 \\
\hline Rao et al. 2014 [47] & $2008-2012$ & hospital & 60 months & Mangalore & 28,373 births & 344 & 121.24 \\
\hline Ronya et al. 2002 [48] & 1999-2000 & hospital ${ }^{\mathrm{b}}$ & 9 months & Wardha & 3000 births & 62 & 206.67 \\
\hline Sachadeva et al. 2014 [49] & 2010 & hospital & 4 months & Rohtak & $\begin{array}{l}2862 \text { live } \\
\text { births }\end{array}$ & 47 & $164.22^{\mathrm{a}}$ \\
\hline Saifulla et al. 1967 [50] & 1966 & hospital $^{\mathrm{b}}$ & 8 months & Chandigarh & 1000 births & 36 & 360 \\
\hline Sarkar et al. 2013 [51] & $2011-2012$ & hospital $^{\mathrm{b}}$ & 12 months & Kolkata & $\begin{array}{l}12,896 \text { live } \\
\text { births }\end{array}$ & 286 & $221.77^{\mathrm{a}}$ \\
\hline Savaskar et al. 2014 [52] & $2011-2013$ & hospital ${ }^{\mathrm{b}}$ & NM & Latur & 10,294 births & 443 & 430.35 \\
\hline Shah and Pensi 2013 [53] & NM & hospital & 9 months & Ahmedabad & 4456 births & 106 & 237.88 \\
\hline Sharma 1970 [54] & 1967-1969 & hospital & 36 months & Mysore & 5554 births & 14 & 25.21 \\
\hline Sharma et al. 1972 [55] & 1963-1964 & hospital & 14 months & Lucknow & 2851 births & 40 & 140.3 \\
\hline Singh and Gupta 2009 [56] & 2002 & hospital & 12 months & Jammu & 9308 births & 140 & 150.41 \\
\hline Singh and Sharma 1980 [57] & 1975-1978 & hospital & 48 months & New Delhi & $\begin{array}{l}6274 \text { live } \\
\text { births }\end{array}$ & 170 & $270.96^{\mathrm{a}}$ \\
\hline Stevenson et al. 1966 [58] & $1961-1964$ & hospital & NM & $\begin{array}{l}\text { Mumbai } \\
\text { (Purandare VN) }\end{array}$ & 39,498 births & 340 & 86.08 \\
\hline Stevenson et al. 1966 [58] & $1961-1964$ & hospital & NM & Kolkata (Mitra KN) & 19,191 births & 59 & 30.74 \\
\hline Swain et al. 1994 [59] & 1988-1989 & hospital & 24 months & Varanasi & 3932 births & 48 & 122.08 \\
\hline Taksande et al. 2010 [60] & $2005-2007$ & hospital ${ }^{b}$ & 31 months & Wardha & 9386 births & 179 & 190.71 \\
\hline Tibrewala and Pai 1974 [61] & 1968-1972 & hospital & 60 months & Mumbai & $\begin{array}{l}12,360 \text { live } \\
\text { births }\end{array}$ & 232 & $187.7^{\mathrm{a}}$ \\
\hline Verma et al. 1991 [62] & 1983-1989 & hospital & 75 months & Ludhiana & 10,000 births & 359 & 359 \\
\hline Verma et al. 1998 [63] & NM & hospital & 36 months & New Delhi & 23,367 births & 433 & 185.3 \\
\hline
\end{tabular}

NM not mentioned

${ }^{a}$ Studies reporting live births only. Prevalence has been reported per 10,000 live births. All other studies reported both live and stillbirths

${ }^{\mathrm{b}}$ Apart from these hospital studies which used radiological, ultrasound and some other investigations, case ascertainment was done only through

physical assessment

live births, anomalies of the musculoskeletal system were highest in both hospital (79.38 per 10,000 live births (95\% CI 32.32-126.44)) and community settings (65.88 per 10,000 live births (95\% CI 23.13-108.63)). The corresponding prevalence of central nervous system defects was lower (28.93 per 10,000 live births (95\% CI 13.6444.22) for hospital-based studies and (26.19 per 10,000 live births (95\% CI 15.55-36.83) for community-based studies).

\section{Prevalence of selected anomalies}

Table 3 presents pooled prevalence of certain frequently reported congenital anomalies among hospital studies. Anencephaly was the most commonly reported anomaly with a birth prevalence of 21.1 per 10,000 births (95\% CI 16.91-25.29) followed by talipes (birth prevalence 17.9 per 10,000 births (95\% CI 15.09-20.71)), orofacial clefts (birth prevalence 14.94 per 10,000 births (95\% CI 12.6417.24)) and hypospadias (birth prevalence 12.20 per 10,000 births (95\% CI 9.79-14.60)) among the 25 studies examining all births occurring in the hospital. Among hospital studies that excluded stillbirth data, the pooled prevalence of talipes (35.08 per 10,000 live births, 95\% CI 16.88-53.29) was higher than anencephaly (17.11 per 10,000 live births, 95\% CI 13.59-20.63) among live births.

\section{Discussion}

Congenital anomalies are not prioritized as public health problems in low income countries as they are considered to be rare conditions that are self-limiting due to the high mortality of affected infants [67]. Another reason for under-prioritization of these conditions is the understanding that most birth defects are not preventable through low-cost primary care strategies, the major approach of public health services of low income countries. In this study, we derived a national estimate of the birth prevalence of congenital anomalies occurring in India, as such data are currently unavailable due to lack of birth defects surveillance. Using a systematic literature search followed by meta-analysis, we derived a pooled prevalence of congenital anomaly affected births of 184.48 per 
10,000 births (95\% CI 164.74-204.21). This prevalence is slightly lower than that reported by the European Surveillance of Congenital Anomalies registry (215.54 affected births per 10,000 births (95\% CI 214.14-216.94)) [68]. In terms of absolute numbers, however, these estimates indicate that congenital anomalies are not rare events in India, as the data suggests that between 421,652 to 522,676 anomaly affected births may be occurring in the country each year. Due to the reporting of stillbirths in hospital-based studies, anencephaly was the most frequently reported anomaly, followed by talipes, orofacial clefts and hypospadias. Neural tube defects (NTDs) like anencephaly are potentially preventable through a low cost primary prevention method of preconception folic acid supplementation [69, 70], but there are as yet no national guidelines on folic acid fortification/supplementation in India. Combined with preconception iron supplementation, this primary care intervention could not only reduce the number of NTDs in the country, but also reduce anemia, a persistent maternal health challenge in low income countries [71]. Community-based studies reported a higher prevalence of musculoskeletal anomalies, with talipes, a potentially treatable anomaly, being reported as the most common congenital anomaly among live births. Thus, in addition to determining the large numbers of affected births, this review identified that the two most commonly reported congenital anomalies were preventable/treatable through low cost methods. For example, the management of talipes through casting is relatively inexpensive, is widely available, and with proper compliance will prevent disability.

Our estimates however have to be considered as best-available data, as there was high heterogeneity among the studies, also reported in previous meta-analysis on NTDs in India [72, 73]. Due to the time-period included in the analyses, the definitions of anomalies varied, although the system-wise categorization of major anomalies was not too deviant from the International Classification of Diseases Version 10 (ICD-10) classifications. Stratified analysis over time did not yield any meaningful trends. It is noteworthy that institutional deliveries were only $26 \%$ in 1992-93 [74], but progressed to 79\% in 2015-16 [75]. Birth defects data from studies conducted during the earlier period could be influenced by the high number of home births, and this could also be a limitation in the estimates. Most of the studies were hospital based. Community based studies were few, and none of the studies mentioned data on home births. For hospital based studies, the catchment areas of hospitals are undetermined due to high patient mobility. Furthermore, the studies included data from large public hospitals which frequently serve as referral centers for high risk mothers and complicated cases. Such methodological issues could be one of the reasons for the different rates observed for anencephaly versus spina bifida, as the latter is the more common condition [68]. Another factor influencing the estimates was that majority of the studies used only clinical assessment for case ascertainment. Incomplete ascertainment may therefore contribute to under-estimation of some anomalies. For example, the low prevalence of congenital heart defects as compared to available registry data could be ascribed to use of only physical examination at the time of birth [68]. Similarly, Down syndrome which is one of the most common birth defects, was not reported in most of the included studies. This discrepancy could be because our meta-analysis included studies that reported birth defects detected in the first week of life, while Down syndrome may be diagnosed after discharge. Another very important source of under-estimation would be the lack of data on termination of pregnancies due to fetal anomaly, as none of the studies reported this data. It should also be pointed out here that only PubMed was used for search of articles, and there may be a possibility that some articles were missed.

Despite these limitations, this review is important, as it is the first to report the magnitude of birth defects in India, and the need to establish a systematic method of surveillance for these conditions. The first point arising from the study is to determine whether surveillance for birth defects in India should be hospital or population based [12]. Data from a network of hospitals forms the cornerstone of existing birth defects registries in developed nations. Apart from systematic data collection, all deliveries occur at hospitals in these settings, and the populations accessing these hospitals are more or less well defined. In contrast, hospital based data will be inappropriate for India due to a number of reasons. Firstly, presence of large numbers of private hospitals would make inclusion of all in the reporting network difficult, leading to a risk of under-estimation of the number of cases. Till date, data reporting is not mandatory from private hospitals in India. Inappropriate inclusion of a major referral hospital, or a hospital providing free services into a birth defects surveillance network could also mislead estimates. Furthermore, unlike the well demarcated populations catered to by hospitals in developed countries, the population catered to by hospitals in India are extremely heterogeneous. There is significant patient mobility, as most healthcare is choice based, and financed through personal expenditure. The hospitals could cater to maternity cases from any part of the country, and these could include mothers from rural or urban areas. Cultural practices, such as preferred delivery at maternal residence could also confound results on geographic distribution of birth defects. All these factors highlight that hospital based surveillance could yield poor quality data, and may even misguide health services 


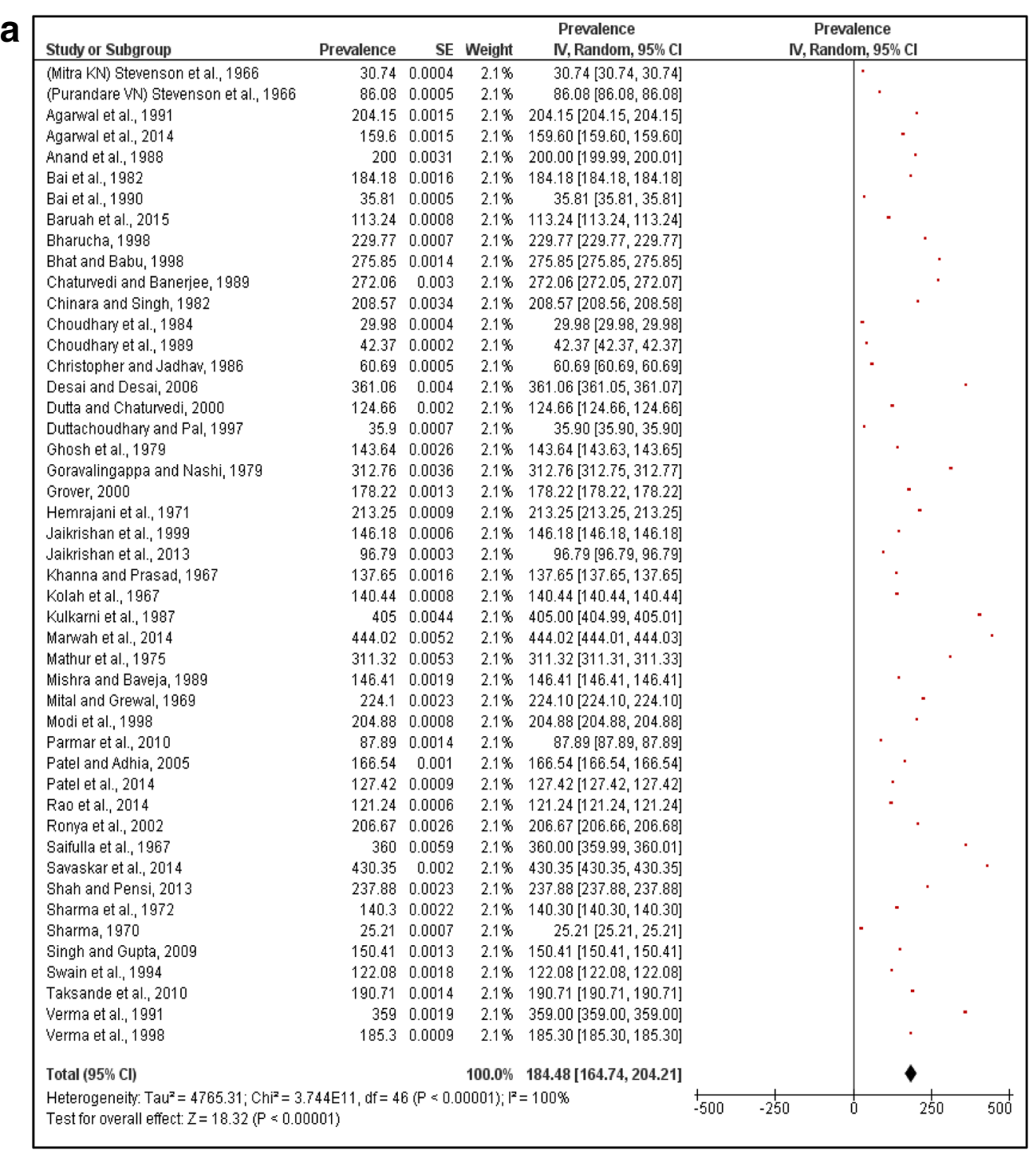

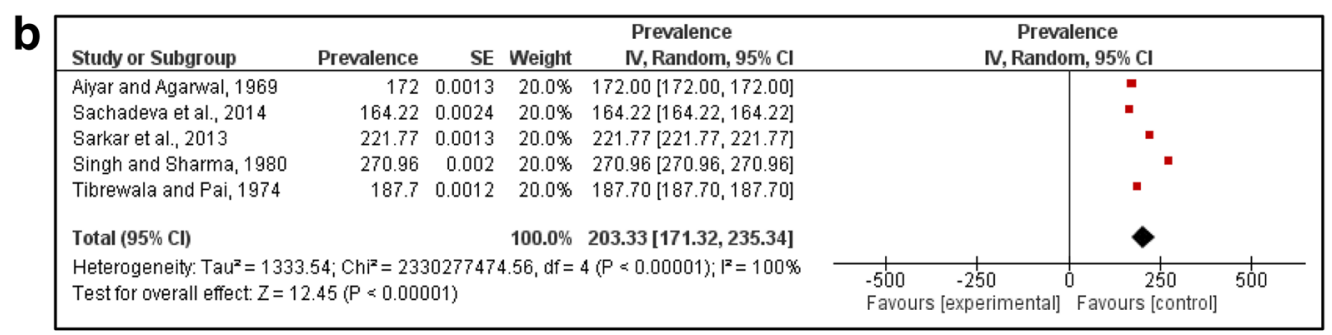

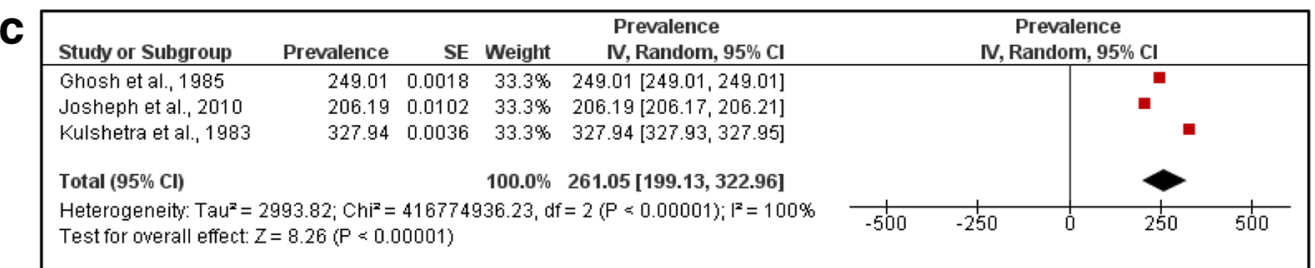

Fig. 2 Pooled prevalence of congenital anomalies. a. pooled prevalence of congenital anomaly affected births (both live and stillbirths) in hospital setting. b. pooled prevalence of congenital anomaly affected live births (hospital setting). c. pooled prevalence of congenital anomaly affected live births (community setting) 
Table 2 Pooled prevalence of anomalies by affected systems

\begin{tabular}{|c|c|c|c|}
\hline System & $\begin{array}{l}\text { Birth prevalence per } 10,000 \\
\text { births ( } n=14 \text { hospital studies) }\end{array}$ & $\begin{array}{l}\text { Live birth prevalence per 10,000 live } \\
\text { births ( } n=3 \text { hospital studies) }\end{array}$ & $\begin{array}{l}\text { Live birth prevalence per } 10,000 \text { live } \\
\text { births ( } n=3 \text { community studies) }\end{array}$ \\
\hline Central nervous system & 75.85 (95\% Cl 58.80-92.90) & $28.93(95 \%$ Cl 13.64-44.22) & 26.19 (95\% Cl 15.55-36.83) \\
\hline Musculoskeletal system & 65.64 (95\% Cl 52.97-78.31) & 79.38 (95\% Cl 32.32-126.44) & $65.88(95 \%$ Cl 23.13-108.63) \\
\hline Cardiovascular system & 27.06 (95\% Cl 20.03-34.09) & 23.04 (95\% Cl 4.69-41.39) & $9.32(95 \% \mathrm{Cl}-0.81-19.45)$ \\
\hline Gastrointestinal system & 50.19 (95\% Cl 42.50-57.87) & $37.72(95 \%$ Cl 26.41-49.03) & a \\
\hline Genitourinary system & 39.08 (95\% Cl 27.86-50.30) & $28.41(95 \%$ Cl 16.18-40.65) & $37.42(95 \%$ Cl 13.14-61.70) \\
\hline
\end{tabular}

${ }^{a}$ Data not analyzed due to misclassification of umbilical hernia as gastrointestinal system anomalies

by suggesting occurrence of clustering of cases due to improper selection of hospitals into the reporting network.

Under such circumstances, true data on birth defects can be obtained from population-based birth defects surveillance, with active surveillance from carefully selected populations, identified in different parts of the country. One of the major functions of birth defects registries is to monitor maternal exposures, such as the prevalence of micronutrient deficiencies, poor maternal health status, agricultural lifestyles or other occupational exposures. India has several high risk situations and areas. Industrial catastrophes like the Bhopal gas tragedy or reports of children with severe birth defects in areas where banned pesticides are being used are examples of populations where communities can be selected, and long term surveillance can be initiated. Many of the risk exposures are shared for several other adverse pregnancy outcomes. Thus, surveillance for birth defects will be an added asset to monitoring maternal and child health outcomes in the country. In addition to selection of population based sites for surveillance, there is the need for adopting standardized definitions and methodology for case ascertainment. Inclusion of data on elective terminations of pregnancy after detection of fetal anomalies and follow-up of infants to include anomalies detected at later ages are important considerations when planning surveillance to reduce under estimation. For countries with limited resources the recently published manual for birth defects surveillance is an excellent tool that enlists steps for facilitating birth defects surveillance [12]. Use of such tools and population based surveillance will permit comparison of data on birth defects in low income countries with those reported from existing congenital anomaly registries.

\section{Conclusions}

In conclusion, this meta-analysis identified that as many as $472,177(421,652$ to 522,676$)$ births affected by congenital anomalies may be occurring in India each year, with anencephaly and talipes being the most frequently reported anomalies. The high reporting of anencephaly suggests the need for a preconception folic acid supplementation programme, but nation-wide studies on implementation have to be conducted. The occurrence of talipes and other anomalies requiring surgical correction suggests the need to strengthen referral services for treatment/management of children born with birth defects. In terms of public health implications, the meta-analysis was unable to identify data on the impact of congenital anomalies on neonatal mortality. The impact of congenital anomalies on childhood disability was however apparent as both anencephaly and talipes are potentially disabling conditions. The analysis identified the need for future studies using standard definitions and methodology so that the data would be globally comparable. In terms of hospital versus population based surveillance, the analysis suggested the need for establishing population based registries with active surveillance for birth defects and maternal risk exposures from carefully selected populations.

Table 3 Pooled prevalence of selected anomalies

\begin{tabular}{lll}
\hline Anomaly & $\begin{array}{l}\text { Birth prevalence per 10,000 births } \\
(n=25 \text { hospital studies })\end{array}$ & $\begin{array}{l}\text { Live birth prevalence per 10,000 live } \\
\text { births ( } n=5 \text { hospital studies) }\end{array}$ \\
\hline Anencephaly & $21.10(95 \% \mathrm{Cl} 16.91-25.29)$ & $17.11(95 \% \mathrm{Cl} 13.59-20.63)$ \\
Exomphalos / omphalocele & $4.65(95 \% \mathrm{Cl} 3.23-6.07)$ & $1.60(95 \% \mathrm{Cl} 0.46-2.74)$ \\
Gastrochisis & $7.00(95 \% \mathrm{Cl} 4.56-18.56)$ & $1.60(95 \% \mathrm{Cl} 1.60-1.60)$ \\
Hypospadias & $12.20(95 \% \mathrm{Cl} 9.79-14.60)$ & $5.39(95 \% \mathrm{Cl} 3.19-7.59)$ \\
Orofacial clefts & $14.94(95 \% \mathrm{Cl} 12.64-17.24)$ & $15.69(95 \% \mathrm{Cl} 11.74-19.63)$ \\
Spina bifida & $5.85(95 \% \mathrm{Cl} 4.48-7.21)$ & $8.45(95 \% \mathrm{Cl} 3.08-13.81)$ \\
Talipes & $17.90(95 \% \mathrm{Cl} 15.09-20.71)$ & $35.08(95 \% \mathrm{Cl} 16.88-53.29)$ \\
\hline
\end{tabular}




\section{Abbreviations}

Cl: Confidence Interval; NM: Not mentioned; NTDs: Neural tube defects

\section{Funding}

University Grants Commission-University with Potential for Excellence Holistic area "Translation research in the health of women and children".

\section{Availability of data and materials}

All relevant data are within the paper.

\section{Authors' contributions}

PB conducted the literature review, data analyses and drafting of the manuscript. AK conceptualized the study, reviewed the search and selection of articles and analyses of the data and contributed in writing the final manuscript. Both authors have read and agree on the final version of the manuscript.

\section{Ethics approval and consent to participate}

Not applicable.

\section{Competing interests}

The authors declare that they have no competing interests.

\section{Publisher's Note}

Springer Nature remains neutral with regard to jurisdictional claims in published maps and institutional affiliations.

\section{Received: 16 February 2016 Accepted: 16 May 2018}

\section{Published online: 25 May 2018}

\section{References}

1. World Health Organization. Global health observatory data. 2015. http:// apps.who.int/gho/data/node.country.country-IND. Accessed 11 Oct 2015.

2. Liu L, Johnson HL, Cousens S, Perin J, Scott S, Lawn JE, et al. Global, regional, and national causes of child mortality: an updated systematic analysis for 2010 with time trends since 2000. Lancet. 2012;379(9832):2151-61.

3. Liu L, Oza S, Hogan D, Perin J, Rudan I, Lawn JE, et al. Global, regional, and national causes of child mortality in 2000-13, with projections to inform post-2015 priorities: an updated systematic analysis. Lancet. 2015;385(9966):430-40.

4. Kar A. Birth defects: an emerging public health issue in the field of child health in India. In: Nimse SB, Agarwal MK, editors. Public health and development in India. New Delhi; 2015. p. 222-36.

5. Dolk H, Loane M, Garne E. The prevalence of congenital anomalies in Europe. Adv Exp Med Biol. 2010;686:349-64.

6. United Nations Children's Fund. The state of the World's children 2015: reimagine the future. 2014. http://www.unicef.org/publications/files/SOWC_ 2015 Summary and Tables.pdf. Accessed 13 Oct 2015

7. Kar A. Birth defects in India: magnitude, public health impact and prevention. JKIMSU. 2014:3(2):7-16.

8. Christianson A, Howson PC, Modell B. Global report on birth defects: the hidden toll of dying and disabled children. New York: March of Dimes Foundation; 2006. http://www.marchofdimes.org/materials/global-report-onbirth-defects-the-hidden-toll-of-dying-and-disabled-children-full-report.pdf. Accessed 13 Oct 2015

9. Kar A. Preventing birth defects in India. Econ Polit Wkly. 2011; XLVI No 48: 21-22.

10. Shannon GD, Alberg C, Nacul L, Pashayan N. Preconception healthcare and congenital disorders: systematic review of the effectiveness of preconception care programs in the prevention of congenital disorders. Matern Child Health J. 2014;18(6):1354-79.

11. World Health Organization, Regional Office for South-East Asia. Prevention and control of birth defects in South-East Asia region Strategic framework (2013-2017). New Delhi, 2013. http://apps.searo.who.int/PDS DOCS/B4941. pdf. Accessed 12 Oct 2015.

12. WHO/CDC/ICBDSR. Birth defects surveillance: a manual for programme managers. Geneva: World Health Organization; 2014. http://apps.who.int/ iris/bitstream/10665/110223/1/9789241548724_eng.pdf?ua=1\&ua=1. Accessed 13 Oct 2015

13. Agarwal SS, Singh U, Singh PS, Singh SS, Das V, Sharma A, et al. Prevalence \& spectrum of congenital malformations in a prospective study at a teaching hospital. Indian J Med Res. 1991;94:413-9.
14. Agrawal D, Mohanty BB, Sarangi R, Kumar S, Mahapatra SK, Chinara PK. Study of incidence and prevalence of musculoskeletal anomalies in a tertiary care hospital of eastern India. J Clin Diagn Res. 2014;8(5):AC04-6.

15. Aiyar RR, Agarwal JR. Observation on the newborn: a study of 10000 consecutive births. Indian Pediatr. 1969;6(11):729-42.

16. Anand JS, Javadekar BB, Belani M. Congenital malformations in 2000 consecutive births. Indian Pediatr. 1988;25(9):845-51.

17. Bai NS, Mascarene M, Syamalan K, Nair PM. An etiological study of congenital malformations in the newborn. Indian Pediatr. 1982:19(12):1003-7.

18. Bai NS, Mathews E, Nair PMC, Sabarinathan K. Lethal congenital malformations: role in perinatal deaths. Indian J Pediatr. 1990;57:581-90.

19. Baruah J, Kurse G, Bora R. Pattern of gross congenital malformations in a tertiary referral hospital in Northeast India. Indian J Pediatr. 2015; https://doi. org/10.1007/s12098-014-1685-z.

20. Bharucha BA. Study of malformations and Down syndrome in India (SOMDI): Bombay region. Ind. J Hum Genet. 1998;4:84-7.

21. Bhat VS, Babu L. Congenital malformations at birth - a prospective study from South India. Indian J Pediatr. 1998;65:873-81.

22. Chaturvedi $P$, Banerjee KS. Spectrum of congenital malformations in the newborns from rural Maharashtra. Indian J Pediatr. 1989;56(4):501-7.

23. Chinara PK, Singh S. East-west differentials in congenital malformations in India. Indian J Pediatr. 1982;49:325-9.

24. Choudhury A, Talukder G, Sharma A. Neonatal congenital malformations in Calcutta. Indian Pediatr. 1984;21(5):399-405.

25. Choudhury AR, Mukherjee M, Sharma A, Talukder G, Ghosh PK. Study of 1,26,266 consecutive births for major congenital defects. Indian J Pediatr. 1989;56:493-9.

26. Christopher LG, Jadhav MA. Perinatal mortality in Vellore part II: lethal malformations, Indian J Pediatr. 1986:53(6):353-7.

27. Desai N, Desai A. Congenital anomalies: a prospective study. Bombay Hospital J. 2006:48(3):442-5.

28. Dutta V, Chaturvedi P. Congenital malformations in rural Maharashtra. Indian Pediatr. 2000:37(9):998-1001.

29. Duttachoudhary A, Pal SK. Congenital anomalies in Durgapur steel plant with special reference to neural tube defect. J Indian Med Assoc. 1997:95(5):135-41.

30. Ghosh AK, Chatterjee S, Piplai C. Congenital malformations in the Bengali newborn babies. Coll Antropol. 1979;3(3):255-60.

31. Goravalingappa JP, Nashi HK. Congenital malformations in a study of 2398 consecutive births. Indian J Med Res. 1979;69:140-6.

32. Grover N. Congenital malformations in Shimla. Indian J Pediatr. 2000;67(4):249-51.

33. Hemrajani KH, Ohri UK, Mehta JB, Saxena S. Congenital malformations in newborn. Pediatr Clin Ind. 1971;6:51-3.

34. Jaikrishan G, Andrews VJ, Thampi MV, Koya PK, Rajan VK, Chauhan PS Genetic monitoring of the human population from high-level natural radiation areas of Kerala on the southwest coast of India. I. Prevalence of congenital malformations in newborns. Radiat Res. 1999;152:S149-53.

35. Jaikrishan G, Sudheer KR, Andrews VJ, Koya PK, Madhusoodhanan M, Jagadeesan CK, et al. Study of stillbirth and major congenital anomaly among newborns in the high-level natural radiation areas of Kerala. India Community Genet. 2013:4(1):21-31.

36. Khanna KK, Prasad LSN. Congenital malformations in the newborn. Indian J Pediatr. 1967:34(230):63-72.

37. Kolah PJ, Master PA, Sanghvi LD. Congenital malformations and perinatal mortality in Bombay. Am J Obstet Gynecol. 1967:97(3):400-6.

38. Kulkarni ML, Mathew MA, Ramachandran B. High incidence of neural-tube defects in South India. Lancet. 1987:1(8544):1260.

39. Marwah S, Sharma S, Kaur H, Gupta M, Goraya SPS. Surveillance of congenital malformations and their possible risk factors in a teaching hospital in Punjab. Int J Reprod Contracept Obstet Gynecol. 2014;3(1):162-7.

40. Mathur BC, Karan S, Vijaya Devi KK. Congenital malformations in the newborn. Indian Pediatr. 1975:12(2):179-83.

41. Mishra PC, Baveja R. Congenital malformations in the newborn - a prospective study. Indian Pediatr. 1989:26(1):32-5.

42. Mital VK, Grewal RS. Congenital anomalies in neonates. Indian J Pediatr. 1969:36(261):356-65

43. Modi UJ, Nayak M, Aiyer S, Bharani S, Master DC, Shah T, et al. Study of malformations and Down syndrome in India (SOMDI): Baroda region. Ind. J Hum Genet. 1998:4:93-8

44. Parmar A, Rathod SP, Patel SV, Patel SM. A study of congenital anomalies in newborn. NJIRM. 2010;1(1):13-7.

45. Patel ZM, Adhia RA. Birth defects surveillance study. Indian J Pediatr. 2005; 72(6):489-91. 
46. Patel D, Patel RV, Singh P. Study of congenital anomalies of the newborn. Paripex- Indian J Res. 2014;3(12):134-6.

47. Rao B, Rao A, Bharathi P. A retrospective study on prevalence of anomalous babies in a tertiary care hospital. Int J Innov Res Dev. 2014;3(6):200-4.

48. Ronya R, Gupta D, Ghosh SK, Narang R, Jain KB. Spectrum of congenital surgical malformations in newborns. J Indian Med Assoc. 2002;100(9):565-6.

49. Sachdeva S, Nanda S, Bhalla K, Sachadeva R. Gross congenital malformation at birth in a government hospital. Indian J Public Health. 2014;58:54-6.

50. Saifulla S, Chandra RK, Pathak IC, Dhall GI. Congenital malformations in newborn. Indian Pediatr. 1967;4(6):251-61.

51. Sarkar S, Patra C, Dasgupta MK, Nayek K, Karmakar PR. Prevalence of congenital anomalies in neonates and associated risk factors in a tertiary care hospital in eastern India. J Clin Neonatol. 2013;2:131-4.

52. Savaskar SV, Mundada SK, Pathan AS, Gajbhiye SF. Study of various antenatal factors associated with congenital anomalies in neonates born at tertiary health care center. International journal of recent trends in. Sci Technol. 2014;12(1):82-5.

53. Shah K, Pensi CA. Study of incidence of congenital anomalies in newborns. Gujarat Med J. 2013;68(2):97-9.

54. Sharma PD. The incidence of major congenital malformations in Mysore. Indian J Pediatr. 1970;37(275):618-9.

55. Sharma B, Bajpai PC, Sharma NI. Some observations on congenital malformations. Indian J Pediatr. 1972;39(296):286-92.

56. Singh A, Gupta RK. Pattern of congenital anomalies in newborn: a hospital based prospective study. JK Sci. 2009;11(1):34-6.

57. Singh M, Sharma MK. Spectrum of congenital malformations in the newborn. Indian J Pediatr. 1980;47:239-44.

58. Stevenson AC, Johnston HA, Stewart MI, Golding DR. Congenital malformations - a report of a study of series of consecutive births in 24 centres. Bull World Health Organ. 1966;34(Suppl):9-127.

59. Swain $S$, Agarwal A, Bhatia BD. Congenital malformations at birth. Indian Pediatr. 1994:31(10):1187-91.

60. Taksande A, Vilhekar K, Chaturvedi P, Jain M. Congenital malformations at birth in Central India: a rural medical college hospital based data. Indian J Hum Genet. 2010;16(3):159-63.

61. Tibrewala NS, Pai PM. Congenital malformations in the newborn period. Indian Pediatr. 1974;11(6):403-7.

62. Verma M, Chhatwal J, Singh D. Congenital malformations - a retrospective study of 10,000 cases. Indian J Pediatr. 1991;58(2):245-52.

63. Verma IC, Anand NK, Kabra M, Menon PSN, Sharma N. Study of malformations and Down syndrome in India (SOMDI): Delhi region. Ind. J Hum Genet. 1998;4:84-7.

64. Ghosh S, Bhargava SK, Butani R. Congenital malformations in a longitudinally studied birth cohort in an urban community. Indian J Med Res. 1985:82:427-33.

65. Joseph N, Subba SH, Naik VA, Mahantshetti NS, Mallapur MD. Morbidity among infants in South India: a longitudinal study. Indian J Pediatr. 2010;77(4):456-8.

66. Kulshrestha R, Nath LM, Upadhyaya P. Congenital malformations in live born infants in a rural community. Indian Pediatr. 1983;20(1):45-9.

67. Christianson A, Modell B. Medical genetics in developing countries. Annu Rev Genomics Hum Genet. 2004;5:219-65.

68. EUROCAT. Prevalence data tables. 2015. http://www.eurocat-network.eu/ AccessPrevalenceData/PrevalenceTables. Accessed 14 Oct 2015.

69. MRC Vitamin Study Research Group. Prevention of neural tube defects: results of the Medical Research Council vitamin study. Lancet. 1991;338(8760):131-7.

70. Berry RJ, Li Z, Erickson JD, Li S, Moore CA, Wang H, et al. Prevention of neural-tube defects with folic acid in China. China-U.S. collaborative project for neural tube defect prevention. N Engl J Med. 1999;341(20):1485-90.

71. Dean SV, Lassi ZS, Imam AM, Bhutta ZA. Preconception care: nutritional risks and interventions. Reprod Health. 2014;11(Suppl 3):S3.

72. Bhide P, Sagoo GS, Moorthie S, Burton H, Kar A. Systematic review of birth prevalence of neural tube defects in India. Birth Defects Res A Clin Mol Teratol. 2013;97(7):437-43.

73. Allagh KP, Shananna BR, Murthy GVS, Ness AR, Doyle P, Neogi SB, et al. Birth prevalence of neural tube defects and orofacial clefts in India: a systematic review and meta-analysis. PLoS One. 2015;10(3):e0118961.

74. International Institute for Population Sciences (IIPS) and Macro International. National Family Health Survey (NFHS-1) 1992-93. http://www.rchiips.org/ nfhs/nfhs1.shtml. Accessed 1 May 2017.

75. International Institute for Population Sciences (IIPS) and Macro International. National Family Health Survey (NFHS-4) 2015-16. http://www.rchiips.org/ nfhs/nfhs4.shtml. Accessed 1 May 2017.

\section{Ready to submit your research? Choose BMC and benefit from:}

- fast, convenient online submission

- thorough peer review by experienced researchers in your field

- rapid publication on acceptance

- support for research data, including large and complex data types

- gold Open Access which fosters wider collaboration and increased citations

- maximum visibility for your research: over $100 \mathrm{M}$ website views per year

At BMC, research is always in progress.

Learn more biomedcentral.com/submissions 